\title{
Rainfall Variability and Its Effect on Yield of Rice in Nigeria
}

\author{
Saliu Akinlabi Tiamiyu* ${ }^{* 1}$, Jude N Eze ${ }^{1}$, Taibat Moji Yusuf ${ }^{2}$, \\ Alhassan Tsako Maji ${ }^{1}$, Samuel Oladele Bakare ${ }^{1}$ \\ ${ }^{1}$ National Cereals Research Institute, Badeggi, P.M.B. 8, Bida, Niger State, Nigeria \\ ${ }^{2}$ Department of Agricultural Economics, Kwara State University, Molete, Kwara State, Nigeria
}

*Email address: satiamiyu2@gmail.com

Keywords: Rice production, climatic environment, rainfall variability, vegetation, Nigeria

\begin{abstract}
Nigerian rice production is mainly rain-fed and naturally prone to vagaries of rainfall variability. The objective of this study was to determine the probable effect of rainfall variability on average yield of rice in Nigeria during a 22-year period (1992-2013). The mean annual rainfall data from major rice producing states and national average rice yields were analyzed using descriptive statistics and regression models. Results of the analysis revealed a significant variation in mean annual rainfall across vegetation grouping in a descending order from swamp forest to Sudan savanna. Mean rainfall was adequate for rice production in all vegetation grouping except Sudan savanna where rainfall was less than the prescribed minimum quantity for rice production. Rainfall was positively related to yield of rice in all vegetation grouping except Sudan savanna but relationship was not statistically significant at 5\% level. It was concluded that annual rainfall variability had statistically negligible effect on national average rice yield. It was recommended that the cultivation of rice should go along with farming practices that aimed at mitigating adverse effects of rainfall variability on the yield of rice especially in the Sudan savanna.
\end{abstract}

\section{INTRODUCTION}

Rice (Oryza sativa) is an important crop that plays a significant role in sustaining national food security as well as creation of employment and income in Nigeria. The crop is grown by farmers in a wide range of production ecologies all over the country. Despite the considerable potential for rice production expansion in all the production ecologies, the rice sector has not been able to satisfy the demand of rice consumers. One of the steps taken towards achieving rice selfsufficiency target includes promotion of yield enhancing technologies especially improved seed varieties [1]. This effort has led to an appreciable increase in rice output [2] but the average national yield of rice remained very low when compared with the potential yield of the released rice seed varieties [3]. There is need to narrow the yield gap through improvement of factors that enable full expression of yield potential of new varieties if the objective of self-sufficiency in rice production is to be achieved. One of such important factors include climatic environment such as temperature, solar radiation and rainfall. The focus of this study was centered on rainfall because rice production system in Nigeria is mainly rain-fed. Rain water supply is the limiting factor to the growth and production of rice in Nigeria as reflected by geographical distribution of rice-growing areas over region of heavy rainfall.

A lot of literatures have treated issues concerning climatic environment and crop production $[4,5,6,7,8,9,10,11,12,13,14]$. Most of these researches focused on the effect of climate change on crop production with little or no attention on climate variability. This study differs from the past studies carried out in Nigeria by focusing on rainfall variability as indices of climate variability.

Climate variability is the short term departure of climate variables from normal either positively or negatively, as against climate change; where changes are observed and / or remain constant for a very long period of time range of 30 years. Climatic variability is very fast, while climate change is very slow [15]. Climate variability is a continuous process which is mostly observed through rainfall and temperature inconsistency [9]. It was reported [16] that rain variability in space and time is one of the most relevant characteristics of climate that has socio- 
economic and ecological implications. Extreme rainfall variability triggers environmental problems such as flood, gully erosion, drought and desertification, which have serious effect on the yield of rice [5]. It was observed [17] that rainfall variability has generated a lot of influence in the level of agricultural products.

Assessment of the effects of rainfall variability on rice yield would assist in formulating policy that would help rice stakeholders to properly adapt rice farming to maximize rice production and consequently raise national output of rice to the level of self-sufficiency. The study is necessary in view of the low national average yield which has to be increased by $100 \%$ if rice self-sufficiency target is to be achieved by 2020 [18]. The specific objective of this study therefore is to determine the effect of annual rainfall variability on the national average yields of rice.

\section{METHODOLOGY}

Study Area. Nigeria is located within the Equator and the Tropic of Cancer on the main latitude and longitude $10^{\circ}$ North and $8^{\circ}$ East respectively. The latitude of Nigeria falls within the tropical zone but the climatic conditions are not entirely tropical in nature. The climatic condition varies in most parts of the country, in the north the climatic condition is arid and to the south there is an equatorial type of climate. The country has a land area of about $923,768 \mathrm{~km}^{2}$ with a wide range of vegetations that are suitable for rice production.

Data Source and Analytical Procedure. Secondary data covering a period of twenty two years, 1992 to 2013 was used for the study. Rainfall data was obtained from Statistical Bulletin of the Central Bank of Nigeria while the yield data was estimated using land area and production data from the website of the United Nations Food and Agricultural Organization [2]. Monthly rainfall data were collected from 23 major rice producing states across all vegetation grouping in Nigeria. Mean annual rainfall was estimated from the monthly mean rainfall in the states selected. Descriptive statistics was used to identify the existence of rainfall variability while regression model was used to analyze effect of rainfall variability on national rice yield. In regression analysis, the quantity of rice yield was made a deterministic function of the rainfall variable [12, 19]. The following equations were estimated using ordinary least square regression:

$$
\begin{aligned}
& \text { Simple linear, } Y=a+b_{1} R_{1}+b_{2} R_{2}+b_{3} R_{3}+b_{4} R_{4}+e \\
& \text { Double-log, } \ln Y=a+b_{1} \ln R_{1}+b_{2} \ln _{2}+b_{3} \ln R_{3}+b_{4} \ln R_{4}+e \\
& \text { Right-sided semilog, } Y=a+b_{1} \ln _{1}+b_{2} \ln _{2}+b_{3} \ln R_{3}+b_{4} \ln _{4}+e \\
& \text { Left-sided semilog, } \ln Y=a+b_{1} R_{1}+b_{2} R_{2}+b_{3} R_{3}+b_{4} R_{4}+e
\end{aligned}
$$

Where: $\mathrm{Y}=$ National average yield of rice (tons/ha); $\mathrm{R}_{1}, \mathrm{R}_{2}, \mathrm{R}_{3}$ and $\mathrm{R}_{4}=$ Mean annual amount of rainfall for swamp forest, rainforest, guinea savanna and Sudan savanna zone ( $\mathrm{mm}$ ) respectively; $\mathrm{a}=$ constant term, $\mathrm{b}_{1}, \mathrm{~b}_{2}, \mathrm{~b}_{3}, \mathrm{~b}_{4}$, = regression coefficients and $\mathrm{e}=$ random error term.

The statistical parameters generated from the above equations were used as criteria for chosen a lead equation that was finally used to assess the effect of rainfall on national rice yield.

\section{RESULTS AND DISCUSSION}

Annual Rainfall Distribution. Table1 presents the results of descriptive statistics of rainfall pattern across the four major vegetation grouping in Nigeria within the period of study, 1992 to 2013. Annual rainfall ranges from 1834 to $2792 \mathrm{~mm}$ in the swamp forest, 1484 to $2140 \mathrm{~mm}$ in the rainforest, 1020 to $1485 \mathrm{~mm}$ in the guinea savanna and 744 to $1126 \mathrm{~mm}$ in the Sudan savanna. The mean annual rainfall across the entire vegetation grouping indicated that rainfall amount was adequate for rice production in the entire zones except Sudan savanna which had less than the prescribed minimum amount of rainfall $(900 \mathrm{~mm})$ for the zone. These may explain the reason for general use of supplementary irrigation to meet up with the rainfall requirement in the Sudan savanna zone. The values of standard deviation and coefficient of variation indicate a clear 
variability in the distribution of annual mean rainfall within the period. The variability of rainfall in the rainforest was relative more consistent. The variability of rainfall was pronounced in the Sudan savanna. The trend of rainfall in the entire vegetation grouping during the period fluctuates from one year to the other as presented in Figure 1. The extent of fluctuation determines the rate of excess rainfall or insufficient rainfall which may trigger incidence of drought, soil erosion or flood that may constitute a major threat to tonnage of rice yield [5]. This finding was in line with the report of similar study [9]. The northward reduction in annual rainfall from swamp forest across to Sudan savanna conforms to the findings in previous studies [20, 21]. Studies [22, 23] have identified different climatological and dynamical features of West Africa to be responsible for such change in rainfall distribution.

Table 1: Distribution of annual rainfall across vegetation grouping

\begin{tabular}{|l|l|l|l|l|}
\hline Statistics & Swamp forest & Rainforest & Guinea savanna & Sudan savanna \\
\hline Mean & 2231.14 & 1838.86 & 1192.74 & 888.18 \\
\hline Minimum & 1834.2 & 1484.4 & 1019.7 & 743.7 \\
\hline Maximum & 2792.1 & 2139.9 & 1484.7 & 1125.9 \\
\hline Range & 958 & 655 & 465 & 382 \\
\hline Standard Deviation & 261.23 & 157.08 & 121.884 & 115.11 \\
\hline Coefficient of variation & $11.7 \%$ & $8.5 \%$ & $10.2 \%$ & $12.9 \%$ \\
\hline Skewness & 0.750142 & -0.27512 & 0.85671 & 0.903001 \\
\hline
\end{tabular}

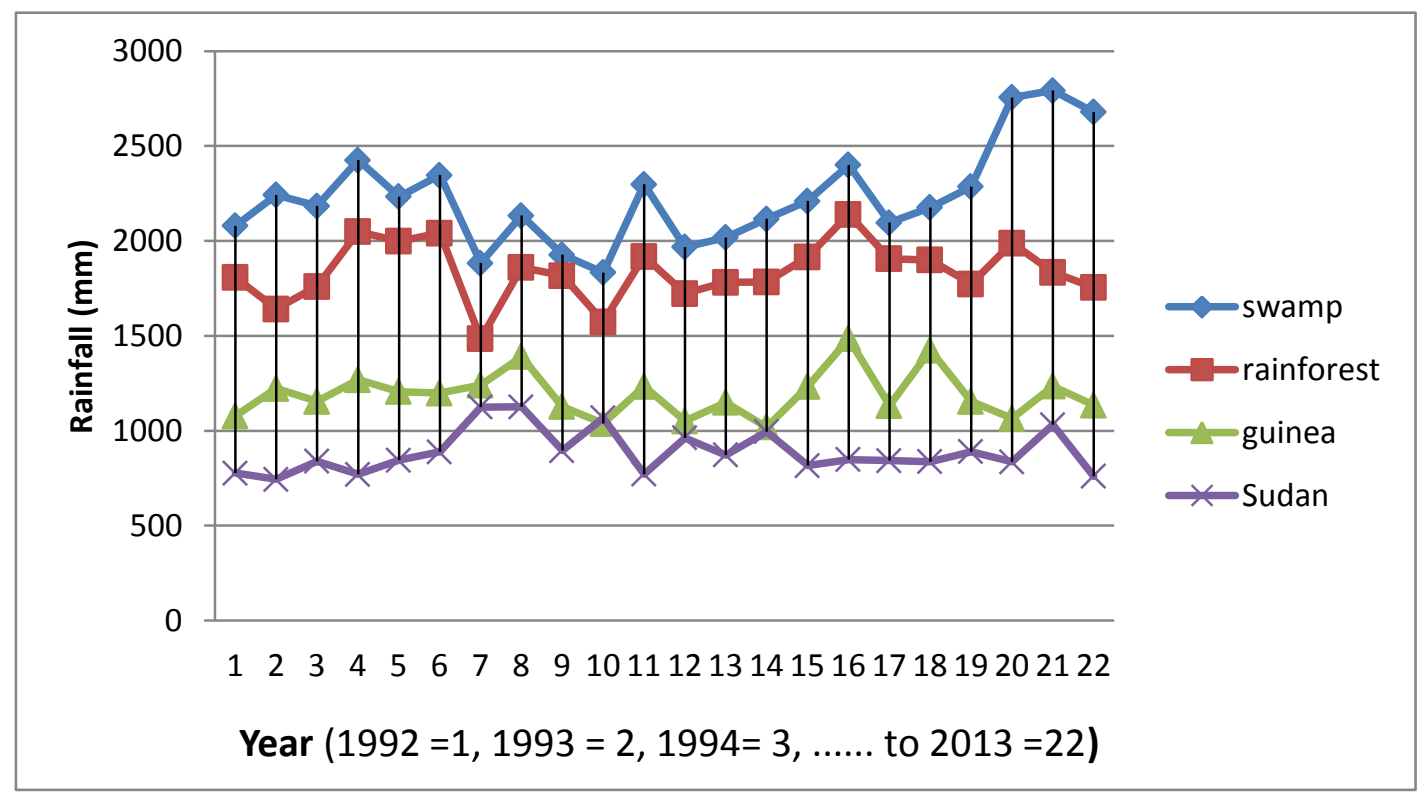

Figure 1: Trend of annual rainfall in Nigeria, 1992 to 2013

Regression Estimates. Table 2 presents the statistical parameters for selecting best fit equation among the estimated regression equations that expressed the relationship between rice yield and rainfall. Based on the values of Multiple R, R-square and F-statistics, linear equation best fit the relationship, and thus selected as lead equation. The multiple R-value of 0.5358 is an indication of moderate correlation [24] between rainfall variability and national yield of rice. The moderate correlation between rainfall and yield of rice corroborates with similar study in Ebonyi and Kwara State [5, 6] The R-square of 0.2872 implies that 29 percent of the variation observed in yield of rice was caused by variation in rainfall in the entire vegetation grouping. The remaining $71 \%$ variation in yield was not explained by variation in rainfall. In other words, other factors not included in the model accounted for the remaining 71 percent variation in yield of rice. F-statistics is not statistically significant implying that significantly smaller proportion of variation in yield was due to variation of rainfall. 
Table 2: Statistical parameters from regression estimate of rainfall and yield data

\begin{tabular}{|l|l|l|l|l|}
\hline Model & Multiple R & R-square & Adjusted R & F-statistics \\
\hline *Linear & 0.5358 & 0.2872 & 0.1195 & 1.7123 \\
\hline Left-sided Semi-log & 0.5260 & 0.2767 & 0.1065 & 1.6258 \\
\hline Double-log & 0.5239 & 0.2744 & 0.1037 & 1.6076 \\
\hline Right-sided semi-log & 0.5330 & 0.2841 & 0.1156 & 1.6863 \\
\hline
\end{tabular}

* Lead equation

The statistical parameters generated from the linear equation are presented in Table 3 . The sign of the coefficients of swamp forest, rain forest and guinea savanna were positive in conformity with apriori expectation since rain which results to soil moisture encourages crop growth and development. The sign of coefficients for the Sudan savanna was negative contrary to apriori expectation. This implies that the higher the mean annual rainfall the lower the yield, or vice versa. This could be explained by the fact that rice production in the Sudan savanna are generally supplemented with irrigated water and whenever there is too much rainfall, river overflow and excess water released from the dam usually cause flooding of rice farms. The flood consequently might lead to low yield through leaching of soil nutrient, erosion of nutrient-rich top soil or complete crop failure through washing away of crops.

Table 3: Statistical parameters of linear regression estimates across the vegetation grouping

\begin{tabular}{|l|l|l|}
\hline Vegetation grouping & Regression coefficient & t-value \\
\hline Swamp forest & 0.00346 & 1.7448 \\
\hline Rainforest & 0.00062 & 1.6206 \\
\hline Guinea savanna & 0.000215 & 0.5256 \\
\hline Sudan savanna & -0.00072 & -1.6294 \\
\hline
\end{tabular}

Generally the coefficients of rainfall variables in the entire vegetation grouping were not statistically significant at 5\% level. The change in yield as a result of rainfall change was statistically negligible. For instance, a one percent increase in rainfall in the swamp forest contributes 0.3 percent increase on yield of rice, while a one percent increase in rainfall in the Sudan savanna contributes 0.07 percent reduction in yield of rice. This implies that rainfall variability was not a major contributing factor to the national average yield of rice.

\section{CONCLUSION}

This study which covered a period of twenty two years has shown the prevalence of rainfall variability in all the vegetation zones. The effect of rainfall variability on the national rice yield across the entire vegetation was not statistically significant during the period of study. Rainfall variability had adverse effect on the yield of rice in the Sudan savanna. The adverse effect, though insignificant during the period of study, is a warning signal to rice stakeholders to take some precautionary measure against unfavorable effects of rain variability on rice yield. There is need to put in place proper structure aim at mitigating the rainfall variability. This step may entail awareness campaign on mitigation measure for rainfall variability specifically and climate change in general. Training on soil and water management in rice production is essential factor in averting the adverse effect of rainfall variability on national rice yield. 


\section{References}

[1] ATA Rice transformation working document. Agricultural Transformation Agenda of the Federal Government of Nigeria, 2011, Pp35

[2] FAO, FAOSTAT database: http://www.faostat.fao,org retrieved on 31 December, 2013

[3] NCRI, Recommended practices for rice production, harvesting and post harvest handling M.E. Abo, E.O. Bright, A.T. Maji, M.N. Ukungwu, I.O. Fatoba, A.A. Ochigbo (Eds.) National cereals Research Institute, Badeggi, Nigeria. 2009. Pp14

[4] R.T. Cruiz, Mitigating impacts of climate change in rice production, Agribusiness Weekly, International rice Research Institute, Philippines, 2009

[5] E.B. Ogbuene, Impact of meterological parameters on rice yield: An approach for environmental resource sustainability in Ebonyi rice farmland, Nigeria. Journal of Environmental Issues and Agriculture in Developing Countries, 2, 2/3, (2010):103-116

[6] R.M. Olanrewaju, Climate and rice production in a part of the Niger River Basin Development Authority, A case study of Edu and lafiagi LGA of Kwara state, Nigeria. Journal of Metereology and Climate science, 8(2) (2010):102-110

[7] T.G. Apata, Effects of Global Climate Change on Nigerian Agriculture: An Empirical Analysis. CBN Journal of Applied Statistics, 2,1 (2011): 31-50

[8] J.A. Ogundele, A. Jegede, Environmental impact of climate change on agricultural production in Ekiti State, Nigeria. Journal of Environmental Issues and Agriculture in Developing Countries, 3, (2011):72-79

[9] E.B. Audu,and D.S. Rizama, Rainfall Variability as Indices of Climate Variability: Evidence from Lokoja and its Environs, Kogi State, Nigeria. International Journal of Applied Research and Technology, 1,6, (2012): $281-288$.

[10] R. H. Rimi, S.H. Rahman, S. Karmakar, S. G. Hussain, Trend Analysis of Climate Change and Investigation on Its Probable Impacts on Rice Production at Satkhira, Bangladesh.Pakistan Journal of Meteorology, 6,11, (2012):37-50

[11] T.D. Akpenpuun, R.A. Busari, Impact of Climate on Tuber Crops Yield in Kwara State, Nigeria. American International Journal of Contemporary Research,3,1, (2013):179-183

[12] C.U. Nwaobiala, and D.O. Nottidge, Effect of climatic variables on cassava farmers' production in Abia State, Nigeria, Nigerian Journal of Agriculture, Food and Environment. 9(4), (2013):57-62

[13] K.A.Oluyole, L.A. Emaku, E.O. Aigbekan, O.O. Oduwole, Overview of the trend of climate change and its effect on Cocoa production in Nigeria. World Journal of Agricultural Research 1(1) (2013): 10-13

[14] B. Koci, and M. Ceylan, Effects of climate change on rice production: The case of Turkey, African Journal of Agricultural Research, 8(23),(2013), pp. 2903-2910

[15] A.S. Adeyemi, Climate Change and Environmental Threats. In Jimoh and Ifabiyi (Eds). Contemporary Issues in Environmental Studies. Haytee Press \&Publishing Co. LTD, Nigeria, 2000, Pp 158.

[16] J.A, Oyewole, A.M. Thompson, J.A. Akinpelu and O.O. Jegede, Variation of Rainfall and Humidity in Nigeria Journal of Environment and Earth Science.4, 2, (2014):29-37

[17] I.A. Madu, C.N. Ayogu, The Effects of Rainfall Variability on Crop Productivity in Northern Nigeria. In R.N.C Anyadike; I.A. Madu and C.K. Ajaero (eds). Proceedings on Climate Change and the Nigerian Environment. Department of Geography, University of Nigeria, Nsukka. 2010, Pp.135 $\& 136$ 
[18] S.A. Tiamiyu, A.F. Lawal and T.M. Yusuf, Trend analysis of production and consumption of rice (Oryza sativa) in Nigeria: A multiperiod approach. Nigeria Journal of Agricultural and Development Economics,3(1) (2015):63-70

[19] B. C. Okoye, G. N. Asumugha, C. A. Okezie, L. Tanko, C. E. Onyenweaku, Econometrics Assessment of the Trend in Cocoyam Production in Nigeria 1960/1961-122003/2006. Agricultural Journal (Medwell online). 3,2, (2008): 99-101.

[20] P.C. Oguntunde, B. J. Abiodun, G. Lischeid, Rainfall trends in Nigeria, 1900 to 2000. Journal of Hydrology, 41(3) (2011):207-218

[21] S.B. Ogungbenro and T. E. Morakinyo, Rainfall distribution and change detection across climatic zones in Nigeria. Weather and Climate Extremes, 5(6) (2014):1-6

[22] J.R. Omotosho, Pre-rainy season moisture build-up and storm precipitation delivery in the West African Sahel. International Journal of Climatology, 28, 7, (2008):937-946

[23] A. Oluleye, Change detection in rainfall anomalies across climatic zones in Nigeria. Journal of Meteorology and Climate Science, 7, (2009):6-10

[24] R. Rangaswamy, A textbook of Agricultural Statistics. New Age International Publishers. 2010, Pp 150. 